ORIENTAL JOURNAL OF CHEMISTRY

An International Open Access, Peer Reviewed Research Journal

www.orientjchem.org
ISSN: 0970-020 X

CODEN: OJCHEG

2020, Vol. 36, No.(2):

Pg. 206-219

\title{
Synthesis of Weinreb and their Derivatives (A-Review)
}

\section{MAHER KHALID*, SHIREEN MOHAMMED and AMIN KALO}

\author{
Department of Chemistry, Faculty of Science, Zakho University, Duhok street, \\ 42002 Kurdistan-Region, Iraq. \\ *Corresponding author E-mail: maher-333@ hotmail.de
}

http://dx.doi.org/10.13005/ojc/360201

(Received: February 21, 2020; Accepted: April 22, 2020)

\begin{abstract}
Due to the largely and an efficient usage of Weinreb amides or $\mathrm{N}$-methoxy-N-methylamides as are remarkable intermediate in the organic synthesis field, the recent review paper provides a considerable development literature survey on the Weinreb amides synthesis. The direct transformation of carboxylic acids,acid chlorides, and esters to aldehydes or ketones employing organometallic reagents do not lead in high yields, since the high reactivity of ketone intermediates toward the organometallic reagents. While, the conversion to the appropriate Weinreb Amides, followed by treatment with the organometallic regent, result the stable expected ketones as the stable initial adduct toward further reactions. Furthermore, Weinreb amides undergo nucleophilic addition and produce a unique and steady five-membered cyclic intermediate which protects the over-addition, leading to a serious transformation.
\end{abstract}

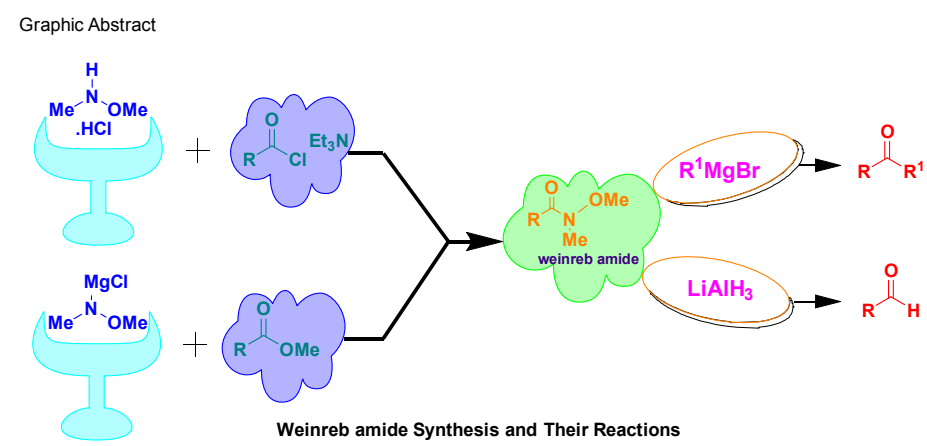

Keywords: Weinreb amides, Weinreb benzamide, Organometallic reagents, $\beta$-trifiuoromethylated enaminones, $\alpha$-amino aldehydes.

\section{INTRODUCTION}

$N$-methoxy- $N$-methylamides or Weinreb amides become a worthy synthetic precursor in organic synthesis ${ }^{1}$ The first synthesis of Weinreb moiety was reported in $1981^{2}$ which performed via

This is an Open Access article licensed under a Creative Commons license: Attribution 4.0 International (CC- BY). Published by Oriental Scientific Publishing Company @ 2018 
treatment of $\mathrm{N}, \mathrm{O}$-dimethyl hydroxylamine with $\mathrm{AlMe}_{3}$ as a coupling reagent. Thereafter, several methods for Weinreb amide synthesis have been reported, like direct transformation of carboxyl group into the corresponding aldehyde or ketone. Exceptionally, the efficiency of Weinreb structure to subject a unique substitution reaction with excess of organometallic reagents in the laboratory and industrial synthesis processes ${ }^{3}$. Weinreb structure reacts closely with organolithium ${ }^{4}$, Grignard reagents ${ }^{5}, \mathrm{LiAlH}_{4}{ }^{6}$ and Wittig reagents to produce aldehydes orketones ${ }^{7}$. Currently, much effort has been devoted to develop their soft and universal synthesis. Such, Weinreb amides can be synthesized from carboxylic acids ${ }^{8}$, acid chlorides ${ }^{9}$, amides $^{10}$, esters ${ }^{11}$, lactones ${ }^{12}$, and anhydrides ${ }^{13}$. Due to the fast evolution of Weinreb amides synthesis and their applications in the last twenty years, it was interesting to review commonalty issue papers in the duration from 2001 to 2009 and detail several neoteric developments of these strategy processes.
In 2001, Giacomelli and co-workers ${ }^{14}$, described a flexible process for the synthesis of hydroxamates, Weinreb amides 4 and hydroxamic acids (Scheme 1). The procedure is used coupling agents like triazine derivatives, carboxylic acids and $\mathrm{N}$-protected amino acids as reactants for preparation of $\mathrm{N}$-methoxy- $\mathrm{N}$-methyl amides (Weinreb amides). However, the organic compound like hydroxamic acids can be formed from the transformation of hydroxamates and Weinreb amides as O-benzyl and $O$-silyl hydroxamates. In addition, handling of reactant for example carboxylic acid 1 with 2-chloro-4,6-dimethoxy-triazine (CDMT) 2 and $\mathrm{N}$-methylmorpholine (NMM) in THF. Subsequently, treatment with $\mathrm{N}, \mathrm{O}$-dimethylhydroxylamine 3 , yields the desired $\mathrm{N}$-methoxy- $\mathrm{N}$-methylamide products 4(Weinreb amide and O-benzyl- or tertbutyldiphenylsilyl hydroxylamine for hydroxamates).

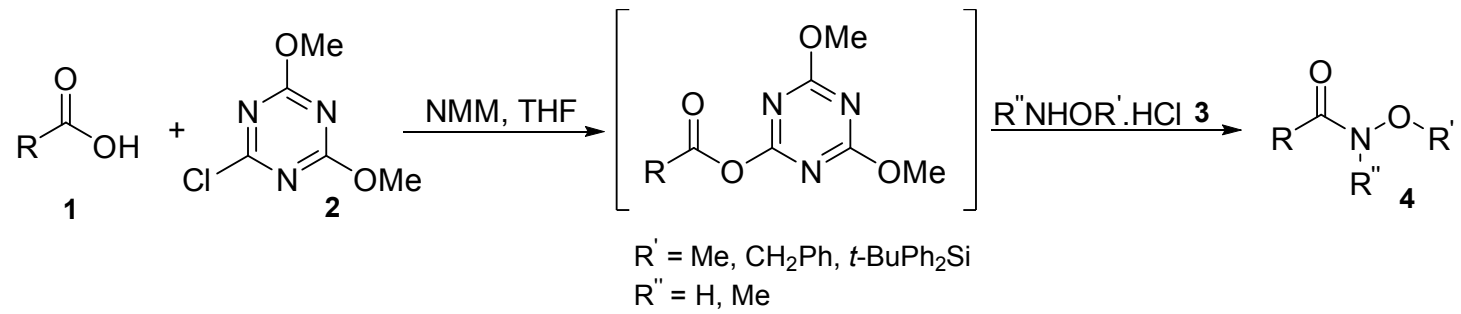

Scheme 1. Synthesis of Weinreb Amides and Hydroxamates

While, Fehrentz and co-workers ${ }^{15}$ detailed a facile synthesis of lipopeptides via using Weinreb $(\mathrm{N}$-methoxy, $\mathrm{N}$-methyl) amide as an aldehyde function precursor on the side chains of Asp or Glu residues(Scheme 2). The reducing of amide 5 by $\mathrm{LiAlH}_{4}$ produce the reactive aldehyde function 6 . Subsequently, the latter can undergo reaction with yilde 7 to form unsaturated or saturated side 8 chains or with various nucleophiles to yield non-coded amino acid residues incorporated into the sequence. Lastly, racemization by enol formation cannot take place when aldehyde function is formed in position of $\gamma$ or $\delta$. This condition is not like form of $\alpha$-amino aldehydes.

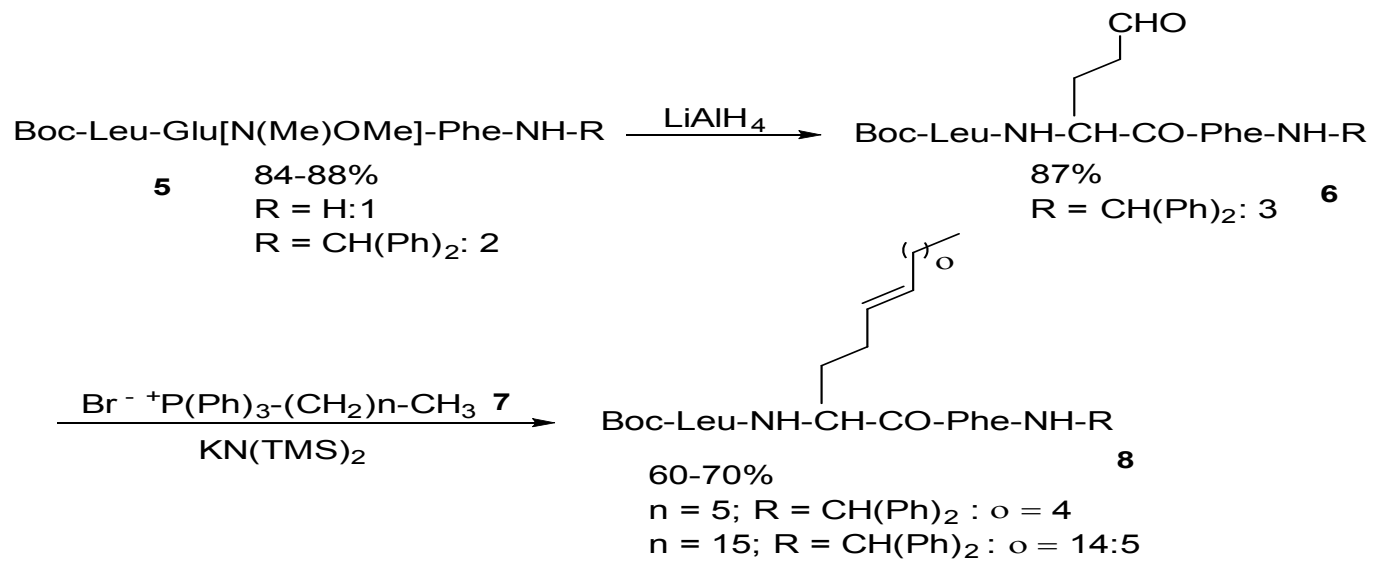

Scheme 2. Synthesis of model peptides and incorporation of the alkyl side chains 
In parallel, Jeong group ${ }^{16}$ reported a novel approach to the synthesis of $\beta$-trifluoromethyl enaminones with good yields (Scheme 3 ). Here, the protocol focused on the treatment of $\mathrm{N}$-methoxy- $\mathrm{N}$ methylbenzamide10 (1.0 eq.) with trifluoropropynyl9
(4.0 eq.)at $-78^{\circ} \mathrm{C}$ with cooling of water and warming to $0^{\circ} \mathrm{C}$, followed by quenching with $\mathrm{H}_{2} \mathrm{O}$ in the presence of a variety of amines 11. Furthermore, using of hydrazine or benzamidine as an amine source in this reaction, afforded the expected pyrazole or pyrimidine products.

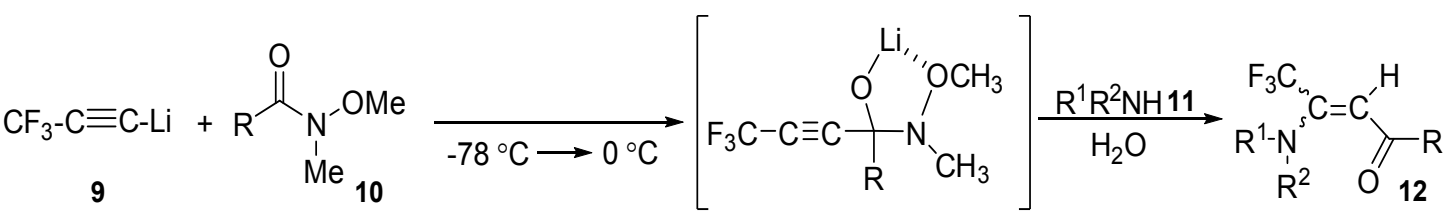

Scheme 3. Preparation of a variety of b-trifluoromethyl enaminones

Furthermore, Lete and co-workers ${ }^{17}$ revealed the efficient role of $\mathrm{N}$-(O-iodobenzyl)pyrrole-2-carboxyamides as internal electrophiles induced proximity effect (CIPE) in Parhamtype cyclization reactions, allowing the efficient construction of the indolizinone nucleus(Scheme 4). So, Li-iodine exchange $14 \mathrm{i}$ could be selected firstly due to the coordination between organolithium and amide group and secondly the stabilization of the aryllithium moiety. Under reaction condition, Weinreb amides 13 have also been successful applied as internal electrophiles in cyclization reactions of organo-lithiums educed from alkyliodides and accessing cyclic ketones 14. Furthermore, this cyclization process, delivered the effective build of the fused pyrrolo[1,2- $b]$ isoquinolines, thieno-[2,3- $f$ ] indolizinones, and pyrrolo[1,2-b]acridinones in high yields. This protocol has also been widespread to heteroaryllithums, allowing a flexible direction to heterocyclic frameworks with prospective pharmacological features that could compete with previously reported strategies.

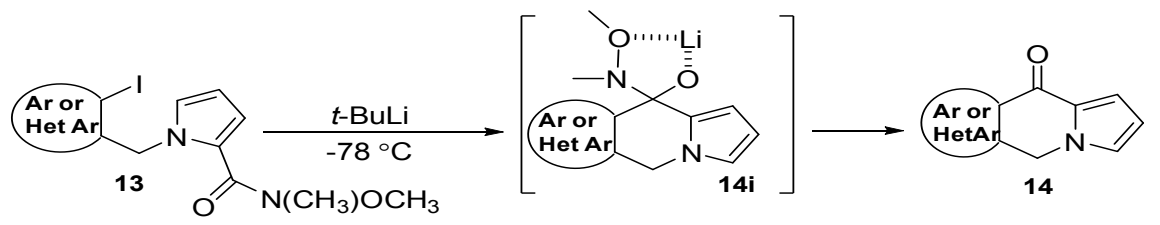

Scheme 4. Synthesis of Fused Indolizinones via Parham-Type Cycliacylation with Weinreb Amides

Independently,Lee and co-worker ${ }^{18}$ illustrated the synthesis of various enantiomericallypure 2-a cylaziridinederivatives(Scheme 5). Generally, this method started firstly through reaction between $\mathrm{N}, \mathrm{O}$-dimethylhydroxylamine hydrochloride16 and readily available $N$-[(R)-(+)- $\alpha$-methylbenzyl]2(S)-aziridinecarboxylic acid menthol ester 15 using $\mathrm{AIMe}_{3}$ as a coupling reagent in DCM affords the Weinreb's amide 17 in excellent yields. Furthermore, the latter was then reacted with different organometallic reagents 18 to provide the expected ketone products 19 with higher yields. Applying this protocol, (1R,2S)-N-Bocnorephedrine, $\mathrm{N}$-Boc-safingol, $\mathrm{N}$-Boc-D-erythrosphinganine, and $\mathrm{N}$-Boc-spisulosine have been prepared in high yields.

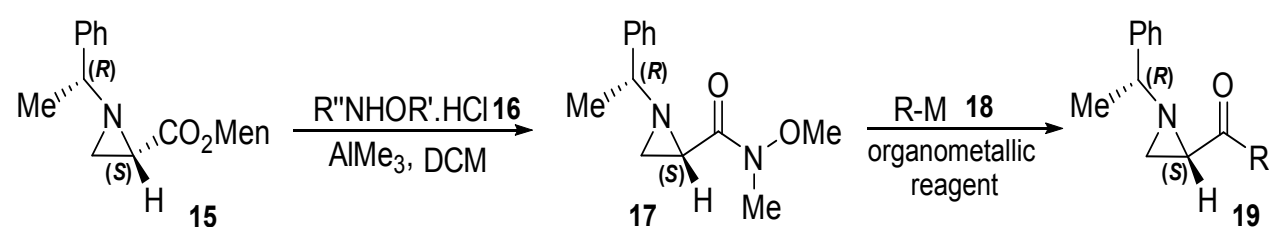

Scheme 5. Synthesis of Enantiomerically Pure 2-Acylaziridines from aziridine-2-carboxylate via Weinreb's

In 2004, Fehrentz and co-workers ${ }^{19}$ described the synthesis of $\alpha$-amino aldehydes linked to the support by their amine function(Scheme 6). This method was completed by reduction with $\mathrm{LiAlH}_{4}$ of the corresponding Weinreb amide linked to the resin. The aldehydes procured were then implicated in Wittig or reductive amination processes. Moreover, the two-step methods, including the conversion of $N$-protected $\alpha$-amino acids 21 to the corresponding Weinreb amides 22 then reduction by $\mathrm{LiAlH}_{4}$, is an effective process for the synthesis of $\mathrm{N}$-protected $\alpha$-amino aldehyde 23 . 


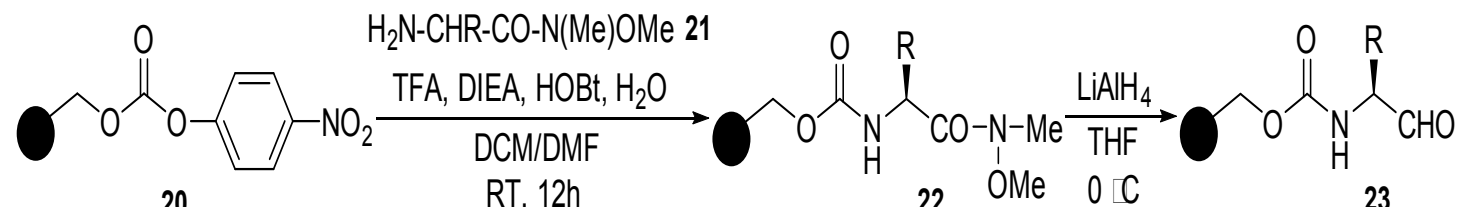
20 RT, $12 \mathrm{~h}$ $22 \mathrm{OMe} O \mathrm{C}$

Scheme 6. Synthsis of a-amino aldehydes linked by their amino function to the solid support

Furthermore, kunishima and co-workers ${ }^{20}$ illustrated the synthesis of Weinreb amides through the reaction of carboxylic acids with $\mathrm{N}, \mathrm{O}$-dimethylhydroxylamine hydrochloride in the presence of 4-(4,6-dimethoxy-1,3,5-triazin-2-yl)-4methylmorpholinium chloride (DMT-MM) in different solvents such as alcohols and acetonitrile, that can dissolve DMT-MM(Scheme 7). In this context, the preparation of Weinreb amides was doneby converting carboxylic acids 24 to the desired Weinreb amide products 26 in higher yields by easily combined with DMT-MM an N,O-dimethylhydroxylamine hydrochloride substrates 25 .

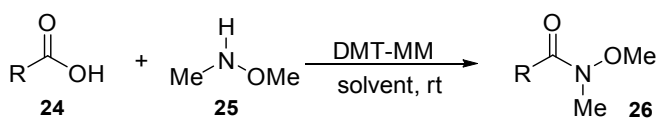

Solvent: Methanol, isopropyl alcohol, acetonitrile.

Scheme 7. Preparation of Weinreb Amides Using (DMT-MM)
Later, Jeong and co-workers ${ }^{21}$ declared amodern and efficient method for the synthesis of $\beta$-trifluoromethylated enone derivatives via reaction of Weinreb amides with trifluoropropynyl lithium, then treated with $\mathrm{H}_{2} \mathrm{O}$ in the mediation of amine derivatives (Scheme 8). Essentially, this method afforded stereo-selectively $\beta$-trifiuoromethylated enaminones with very good yields. The latter was reacted with satirically less hindered amine derivatives to produce amine products with high stereo specifically. In addition, the reaction mixture of $\mathrm{N}$-methoxy- $\mathrm{N}$-methylbenzamide $28(1$ eq.) and trifluoropropynyl lithium $27\left(2\right.$ eq.) at $-78^{\circ} \mathrm{C}$ then $0^{\circ} \mathrm{C}$, followed by addition of $\mathrm{H}_{2} \mathrm{O}$ in the mediation of amine derivatives 29, $\beta$-trifiuoromethylated enaminone products 30 were resulted with perfect stereo-specifically.

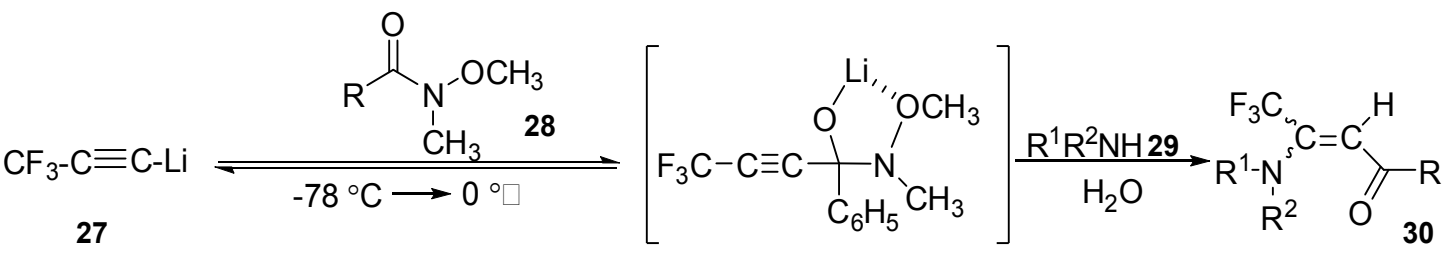

Scheme 8. Preparation of b-trifluoromethylated enone derivatives

Moreover, Franck and co-workers ${ }^{22}$ examined the cycloaddition of Weinreb amide bearing nitrile oxide/nitrones functional groups with a scope of dipolarophiles (Scheme 9). However, there are two synthetic route options for the synthesis of Weinreb amide nitrile oxide 39 and nitrones 41 . Firstly, Weinreb amide nitrile oxide 39 was prepared by reaction of trans-cinnamic acid 31 in two procedures. Cinnamic acids 33 is displayed to ozonolysis to give the expected compound separated as the mixture of aldehyde 33 and its hemiacetal, in methanol as a co-solvent for this process. This mixture of the expected products, anyway, was simplyisolated from benzaldehyde through flash chromatography. Handling of aldehyde 34 with hydroxylamine hydrochloride 35 gave with quantitative yield of the crude Weinreb amideoxime 36 . The latter 38 can be transformed to nitrile oxide 39 through the classical chlorination method in the presence of $\mathrm{NCS} 37$ thenelimination of $\mathrm{HCl}$ usesEt ${ }_{3} \mathrm{~N}$ (Synthetic Option 1). Subsequently, the Weinreb amide-nitrone 41 was prepared by reaction between Weinreb aldehyde 34 and $N$-benzyl hydroxylamine hydrochloride 40 . The crude nitrone 41 was directly used in the cycloaddition process without additional purification(Synthetic Option 2).

While Dake and co-workers ${ }^{23}$ described an appropriate strategy for the transformation of bulky carboxylic acids 42 to $\mathrm{N}$-methoxy- $\mathrm{N}$-methylamides 45. Therefore, this transformation can be efficiently completed with of methanesulfonyl chloride 
43(1.1 eq.), triethylamine (3 eq.), and $N$-methoxy$\mathrm{N}$-methylamine 44(1.1 eq.) (Scheme 10). The percentage yields for this process range were up to $88 \%$. Remarkable, removal of, $N$-methoxy- $N$ methylmethanesulfonamide as the major byproduct in such reactions, was done by set it under vacuum for overnight. Furthermore, this process was necessaryfor dissolving their individual synthetic problem, and could demonstrate valuable for other practitioners of organic chemistry.

\section{Synthetic Option 1:}
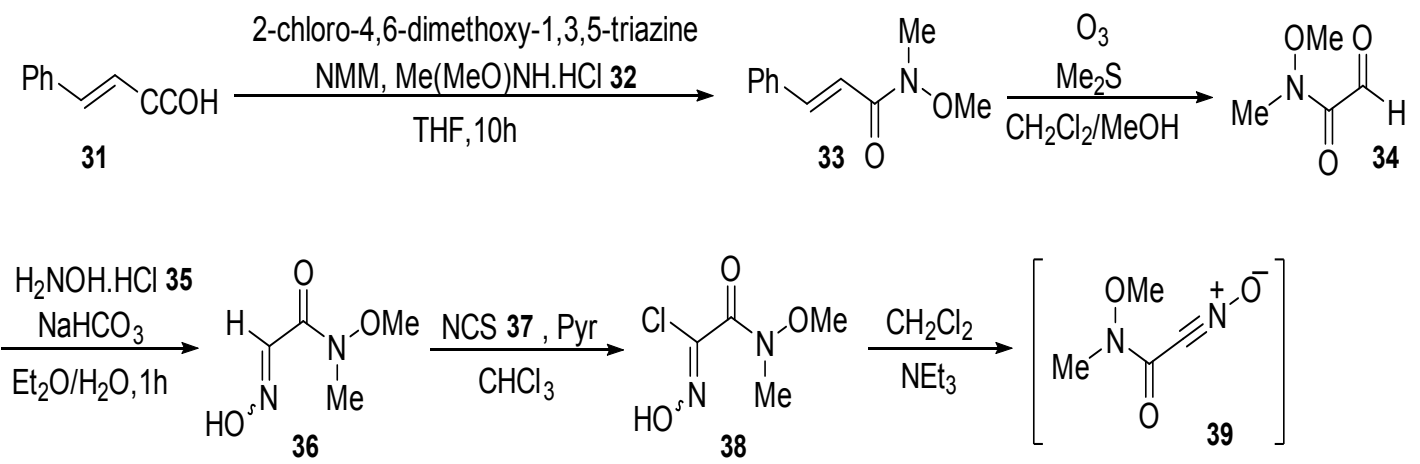

\section{Synthetic Option 2:}

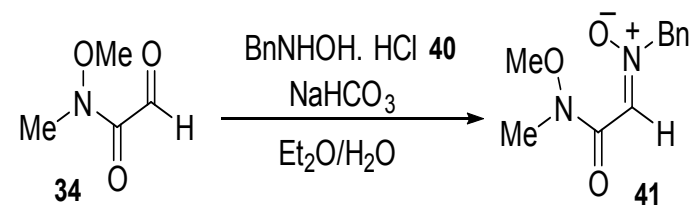

Scheme 9. Preparation of Weinreb Amide-Nitrile Oxide and Weinreb Aminde Nitrones

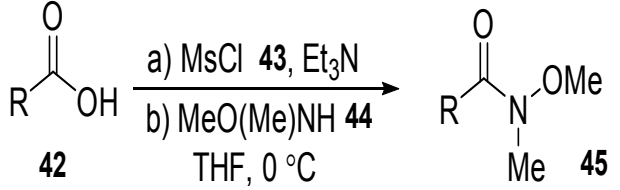

Scheme 10. Formation of Hindered Weinreb Amides

In 2005, Lee and co-workers ${ }^{24}$ provided a novel preparation of $\mathrm{N}$-methoxy- $\mathrm{N}$-methylamides through the reaction of S-2-Pyridyl Thiocarbamate with Grignard reagents (Scheme 11). The authors suggested to prepare $\mathrm{N}$-methoxy- $\mathrm{N}$-methylamides
50 in the convenience of one step operation, and also can be recently made through the reaction of S-2-pyridyl Thiocarbamate 48 with Grignard reagents 49 under mild conditions. Subsequently, preparation of S-2-Pyridyl Thiocarbamate 48 throughreaction of $N, O$-dimethylhydroxylamine hydrochloride 47 with S,S-di(2-pyridyl) dithiocarbonate 46 in the presence of triethylaminein $\mathrm{DCM}$ at $0^{\circ} \mathrm{C}$, However, the successful synthesis of $\mathrm{N}$-methoxy- $\mathrm{N}$-methylamides 50 using S-2PyridylThiocarbamate reliesbroadly on the selective of 2-thiopyridyl group in the substitution reaction.

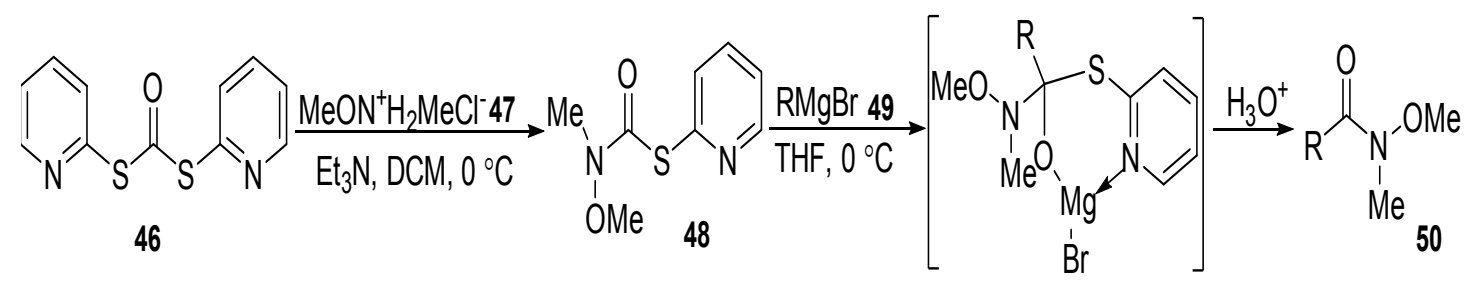

$\mathrm{R}=\mathrm{CH}_{3}\left(\mathrm{CH}_{2}\right)_{7}, c-\mathrm{C}_{6} \mathrm{H}_{11}, \mathrm{C}_{6} \mathrm{H}_{5}-\mathrm{C} \equiv \mathrm{C}, \mathrm{C}_{6} \mathrm{H}_{5}, 0-\mathrm{CH}_{3}-\mathrm{C}_{6} \mathrm{H}_{4}, 0-\mathrm{CH}_{3}-\mathrm{C}_{6} \mathrm{H}_{4}, p-\mathrm{CH}_{3}-\mathrm{C}_{6} \mathrm{H}_{4}, p-\mathrm{CH}_{3}-\mathrm{O}-\mathrm{C}_{6} \mathrm{H}_{4}, p-\mathrm{Cl}_{-} \mathrm{C}_{6} \mathrm{H}_{4}$, $\alpha$-Naphthyl, 2-Thienyl 
Later, Davis and co-workers ${ }^{25}$ reported innovative strategy for the preparation of $\mathrm{N}$-Sulfinyl $\beta$ Amino carbonyl compounds (Scheme 12). Here, an inclusive methodology protocol has been submitted by the addition of the potassium enolate of $\mathrm{N}$-methoxy$N$-methylacetamide 52 to sulfinimines 51 or by handling $N$-sulfinyl $\beta$-amino esters 53 with lithium $\mathrm{N}, \mathrm{O}$-dimethylhydroxyamine 54 , produce the related $N$-sulfinyl $\beta$-amino Weinreb amide products with high diastereo selectivity. This new method reveal as a common resolution to the problem of $\beta$-amino carbonyl compounds 57 synthesis, via reaction with different organometallic compounds 56 which are significantly moieties and ingredients of natural products. Additionally, this methodology performed a universal solution to the matter of $\beta$-amino carbonyl syntheses, which are remarkable chiral frameworks and components of natural products.

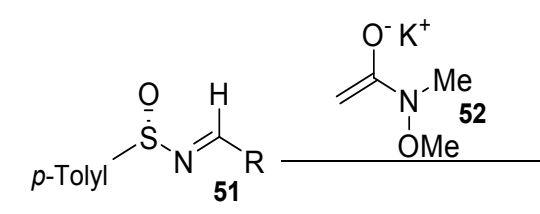

or

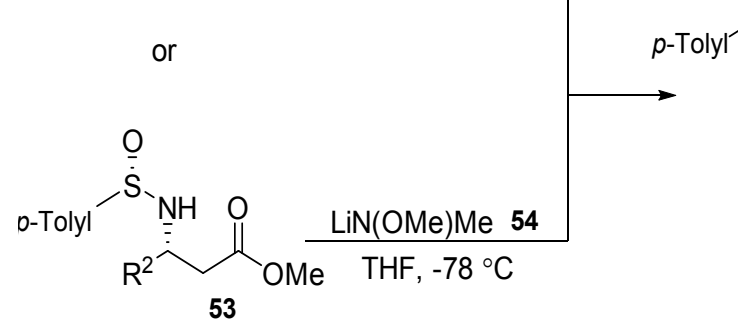

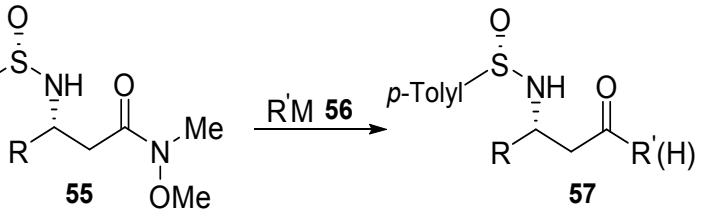
$N$-Sulfinyl $\beta$-amino Weinreb amides
$N$-Sulfinyl $\beta$-amino aldehydes and ketones

Scheme 12. Asymmetric Synthesis of b-Amino Carbonyl Compounds with $N$-Sulfinyl $\beta$-Amino Weinreb Amides

Murphy and co-workers ${ }^{26}$ demonstrated the direct transformation of Weinreb Amides $(N$ methoxy- $N$-methylamides) to the related ketones through unusual Wittig reaction (Scheme 13). Moreover, this reaction proceeds through treatment of $\mathrm{N}$-methoxy- $\mathrm{N}$-methylamides 58 with alkylidenetriphenylphosphoranes 59 , followed by one-pothydrolysis of the intermediate to produce the corresponding ketone products 60 . Furthermore, this conversion takes place in a way which prevent the quite reactivity of organometallic reagents. Finally, the reaction conditions were considerably reasonable than the transformation route in the presence of organometallic reagents. In addition Its chemo selectivity is mostly observed in the pure conversions of cyano- or halo-substituted substrates.

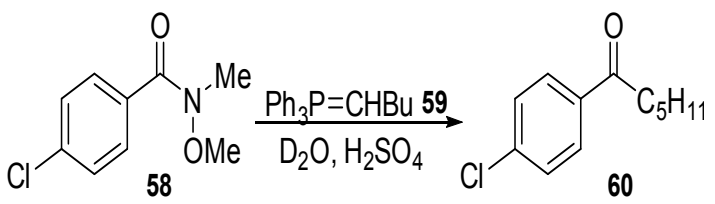

Scheme 13. Conversion of $\mathrm{N}$-Methoxy- $\mathrm{N}$-methylamindes to Ketones via Wittig Reaction

Moreover, Conrad and co-workers ${ }^{27}$, revealed An effective one-pot method for $\alpha$-amino ketone 63 synthesis through the arylation of
Weinreb amides whereas retaining chirality of the main amide (Scheme 14). Actually, this reaction improved quietness when i- $\mathrm{PrMgCl}$ (2.5 eq.) was straightway added into the solution of Weinreb amide 61 and 3,5-bis (trifluoromethylbromobenzene 62 at $10^{\circ} \mathrm{C}$. The method, distinctly proves that the Knochel magnesiztions are kinetically going slower than deprotonating comparing to organolithium transmetallations.

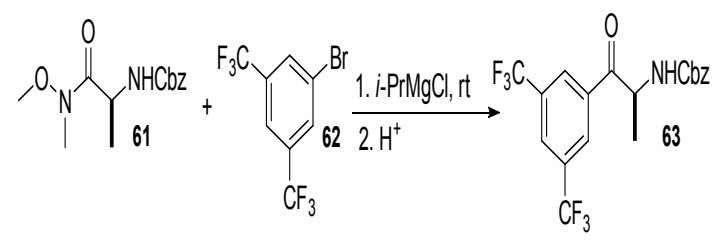

Scheme 14. One-pot process for a-Amino Aryl Ketone Synthesisi

In 2006, Pelkey and co-workers ${ }^{28}$ have reported a functional synthetic path to 3,4disubstituted pyrrole-2-carboxaldehydes and 3-pyrrolin-2-ones starting from Pyrrole Weinreb Amides (Scheme 15). Here, aregion-controlled preparation of 3,4-disubstituted pyrrole-2carboxaldehydes was achieved over two main steps using acyclic substrates. (i) Barton-Zard pyrrole method through reaction between $N$-methoxy- $N$ - 
methyl-2-isocyanoacetamide 66 and $\beta$-nitroacetates 64 or $\alpha$-nitroalkenes 65 , providing pyrrole Weinreb amides 67 ; (ii) reduction reaction step of pyrrole2-carboxaldehydes 68; and (iii) the regioselective oxidation step of 3-pyrrolin-2-ones 69. Remarkably, this method licensed to the preparation of non-syn metrical pyrrole-2-carboxaldehydes 68 and 3-pyrrolin2-ones 69 with estimate to substituent'sexisting in the $\alpha$-positions, and this could demonstrate helpful for the synthesis of oligopyrrole compounds.<smiles>[R]C=C([R1])[N+](=O)[O-]</smiles>

Scheme 15. Synthesis of Pyrrole-2-carboxaldehydes and 3-Pyrrolin-2-ones form Pyrrole Weinreb Amindes

In parallel John A. Murphy and co-workers ${ }^{29}$ detailed the efficient transformation of Weinreb amides of formic acid to aldehyde products 72 under Wittig reaction conditions (Scheme 16). Under the optimal reaction conditions, treatment of phosphorus on the Weinreb amide of formic acid 70 with organometallics like organolithium or Grignard reagents 69 . The qualification of this method is imputed to the stability of tetrahedral intermediate, that does not undergo fragmentation to the expected aldehyde product 72 until work-up.

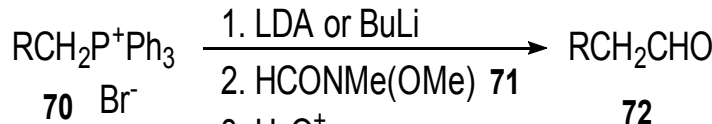

$$
\begin{aligned}
& \text { 3. } \mathrm{H}_{3} \mathrm{O}^{+}
\end{aligned}
$$

Scheme 16. Preparation of Aldehyde via Wittig Reaction

Furthermore, Buchwald and co-workers ${ }^{30}$ developed the efficient protocol for the synthesis of Weinreb amides through Pd-catalyzed aminocarbonylation of aryl bromide substrates at atmospheric pressure(Scheme 17). The reaction is the transformation of aryl bromides 73 to the corresponding Weinreb amide products 76 under 1 atm of $\mathrm{CO} 75$ and catalytic conditions. A wide range of functional groups, including electron-deficient, -neutral, and -rich aryl bromides 72 were tested and shown their effectiveness transformation to the desired products 76 .

Meanwhile, Collum and co-workers ${ }^{31}$ described acylation mechanism of Weinreb amide with Lithium phenylacetylide (Scheme 18). The protocol here described the reaction of dimeric lithium acetylide via a mono solvated monomerbased transition structure. The sturdy tetrahedral intermediate stylesconsecutive a C1 2:2 mixed tetramer in the presence of excess lithium acetylide 78 and a 1:3 (alkoxide-rich) mixed tetramer. The stabilization of the mixed tetramers iscompatible with a declared auto inhibition. In addition, the tetrahedral intermediate reacts with lithium phenylacetylide (PhCCLi) 78 in the presence of Weinreb amide 77as a reagent to form ketone compound derivative 79 .

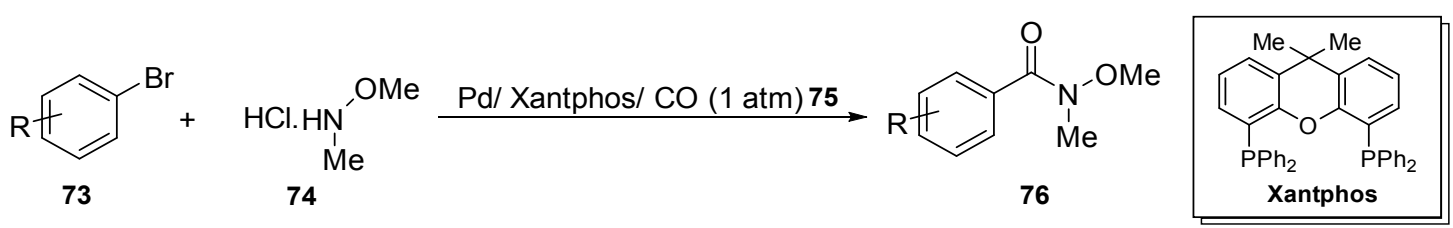

Scheme 17. Preparation of Weinreb Amindes via Pd-Catalyzed Aminocarbonylation of Aryl Bromides

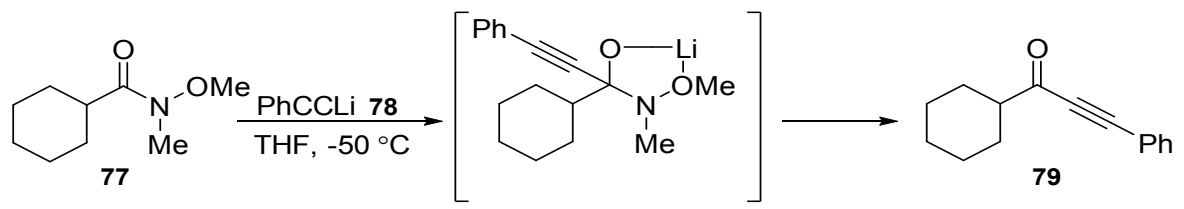

Scheme 18. Acylation of Lithium Phenylacetylide with a Weinreb Aminde 
Independently, John Nielsen and coworkers ${ }^{32}$ detailed the preparation of (E)- $N$-methoxy$N$-methyl- $\beta$-enaminoketoesters and also novel synthetic pioneers for the region-selective synthesis of heterocyclics(Scheme 19). First, Weinreb amides 81 treat with the $\mathrm{Li}$ - or $\mathrm{Na}$ - acetylide of ethyl propynoate 80 in a hitherto acyl substitution-conjugate addition series to produce (E)- $N$-methoxy- $N$-methyl- $\beta$ enaminoketoesters 82 , second, this protocol affords a variety access to violently functionalized heterocyclics, inclusive pyrazoles 84 through region-selective cyclo-condensations with hydrazine compounds 83 applying microwave-assisted reaction.<smiles>[R]C(=O)N(C)OC</smiles>

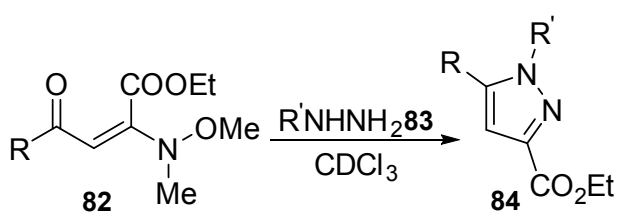

Scheme 19. Synthesis of $N$-Methoxy- $N$-methyl-b-enaminoketoesters

In 2007, Davis and co-workers ${ }^{33}$ reported the asymmetric preparation of syn- $\alpha$-substituted $\beta$-amino acidsthrough a reaction of pro-chiral lithium enolates of Weinreb amides and sulfinimines ( $N$-sulfinyl imines)(Scheme 20). The protocol here first focused on the reaction of sulfiniminederived $\alpha$-substituted $\beta$-amino Weinreb amide with organometallic compounds. While the direct synthesis of major $\alpha$-substituted $\beta$-amino Weinreb amide products 87 proceeded through the addition of a prochiral Weinreb amide enolate 86 to a sulfinimine 85. Moreover, the sulfinimine-derived chiral building blocks are considered as significant pioneers of syn- $\alpha$-substituted $\beta$-amino acid derivatives, through hydrolysis, reduction, and reaction with Grignard reagents, individually.<smiles>CON(C)C(=O)Cc1ccccc1</smiles>

Scheme 20. Synthesis of syn-a-Substituted a-Amino Ketones by Using Sulfinimines and prochiral Weinreb Amide Enolates

Though, Kim and co-workers ${ }^{34}$ suggested a novel and effective procedure for the transformation of different carboxylic acids to their analogical Weinreb amides employing triphosgene as an acid activator (Scheme 21). This reaction encompasses the treatment of carboxylic acid 89 with triphosgene 90 to give an acid chloride or anhydride, followed by handling with $\mathrm{N}, \mathrm{O}$-dimethylhydroxylamine 91 to produce the expected Weinreb amide 92. The current method afforded high yields, short reaction time, and workable accessibility.

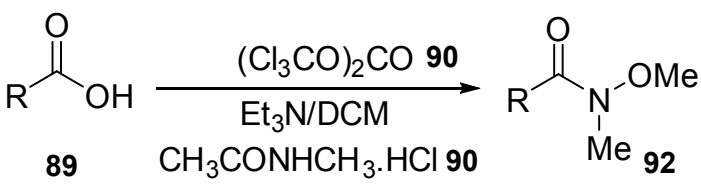

Scheme 21. Synthesis of Weinreb Amides from Carboxylic Acids Using Triphosgene
While, Jeong and his group ${ }^{35}$ reported dynamic one-pot preparation of unusual $\alpha$, $\beta$-dichloro- $\beta$-trifluoromethylated enones (Scheme 22). The stages of protocol start with the reaction of Weinreb benzamides 94 and trifluoropropynyllithium 93 in THF at -78 to $0^{\circ} \mathrm{C}$, followed by handling with trifluoromethanesulfonyl chloride 95 to produce $\alpha, \beta$-dichloro- $\beta$-trifluoromethylated enones 96 in moderate yields. While the reaction of $\alpha, \beta$-dichloro$\beta$-trifluoromethylated enones 96 with substitute amidines 98 or hydrazinereagents 102 in reflux mixture of 1,4-dioxane/ $\mathrm{CH}_{3} \mathrm{CN}$ produced trifluoromethylated chloropyrimidines 99 and chloropyrazoles 103 in acceptable yields. Furthermore, the coupling reactions of trifluoromethylated chloropyrimidines 99 with substituted phenylstannane and allylstannane 100 in $\mathrm{CH}_{3} \mathrm{CN}$ using $\mathrm{Pd}\left(\mathrm{PPh}_{3}\right)_{4}$ catalyst under microwave-assisted conditions, provided the desired 
phenyl and allyl substituted pyrimidine products 101 in very good yields. While the same conditions were applied with chloropyrazoles103, but did not lead to the product 104 .

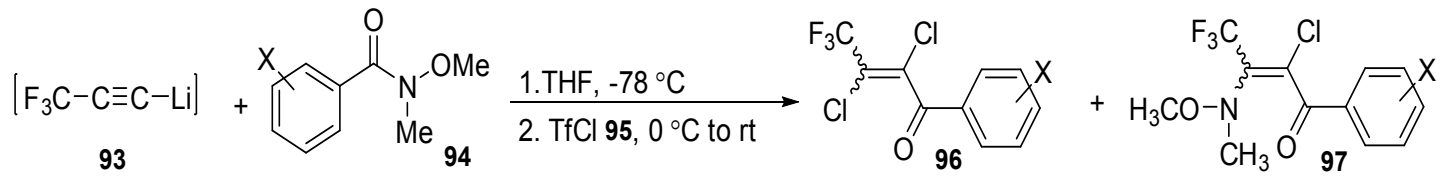

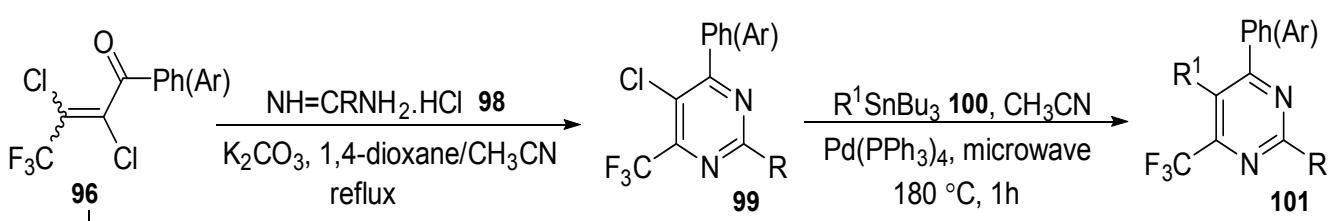

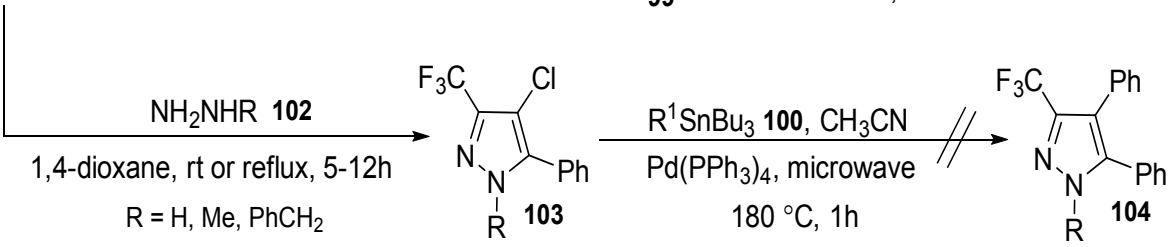

Scheme 22. Synthesis of novel a,b-dichloro-b-trifluoromethylated enones and trifluoromethylated heterocycles

In 2008, Prandi and co-workers ${ }^{36}$ described the preparation of newfangled species of heterocyclic Weinreb amides through aminocarbonylation reaction of heterocyclic-derived triflates in the presence of $\mathrm{Pd}$ catalyst (Scheme 23). This reaction proceeded through the straight forward conversion of lactone-, thiolactone and lactam-derived triflates 105 into the corresponding morpholineor $N$-methoxy$\mathrm{N}$-methyl Weinreb amides 107 . The protocol here suggested to proceed through using CO 75 under mild conditions. However, the amides steadily reacted with nucleophiles 108 to yieldthe desired heterocycle products109. This new protocol discloses the outlet to important dynamically heterocyclic scopes that are favorable as building blocks in total syntheses, and the suggested methodology could be convenient profit for the dienone synthesis, as helpful moieties for Nazarov cyclization.

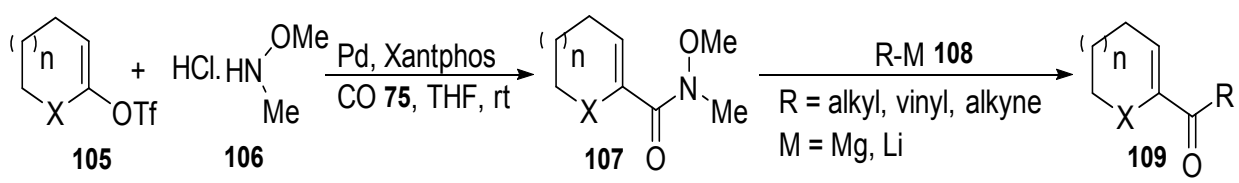

$X=0, N-E W G, S, C$

$n=1,2$

Scheme 23. Synthesis of Weinreb Amides via Pd-Catalyzed Aminocarbonylation of Heterocyclic-Derived Triflates

Next, Somfai and co-workers ${ }^{37}$ reported an efficient and diastereoselective synthesis of aryl glycines 112 from Weinreb amides employing $\alpha$-arylation process(Scheme 24$)$. In such reaction, a novel $\alpha$-arylation reaction proceeds smoothly through the reaction between amideas electrophile
110 andaryl Grignard reagents as nucleophile 111 in the presence of LDA as a base in THF at low temperature. The mechanism of this reaction starts with deprotonating and the generation of enolate, followed by elimination tBuO. While the nucleophilic addition of the Grignard reagent to form amide.<smiles>C=CCN(CC(=O)N(C)OCCCC)Cc1ccccc1</smiles>

1. LDA, THF, $-78^{\circ} \mathrm{C}$

2. $\operatorname{ArMgX} 111,-78$ to $25 \stackrel{C}{\longrightarrow}$<smiles>C=CCN(Cc1ccccc1)C([Al])C(=O)NO</smiles>

Scheme 24. Synthesis of Aryl Glycines by the a Arylation of Weinreb Amides 
Recently, Li and co-workers ${ }^{38}$, described the synthesis of diverse chiral $N$-phosphonyl $\beta$-amino Weinreb amides 115 viareaction of chiral $N$-phosphonyl imines 113 with the lithium enolate of $N$-methoxy- $N$-methylacetamide 114 employing mild conditions (Scheme 25). Generally, the deprotonation base and presence of protection groups on chiral $\mathrm{N}$-phosphonyl imines were the pivotal success of such reactions. Commonly, $N$-phosphonyl imines uses as electrophiles 113 for some nucleophilic addition reactions, like aza-Darzens, aza-Henry reaction, and allylmagnesium bromide based addition, various wide of Weinreb amides were prepared in excellent yields (up to 98\%) with high diastereoselectivities. Furthermore, the ultimate structures were uniquely specified by the transformation the products into original samples and equal their optical rotation assessments.
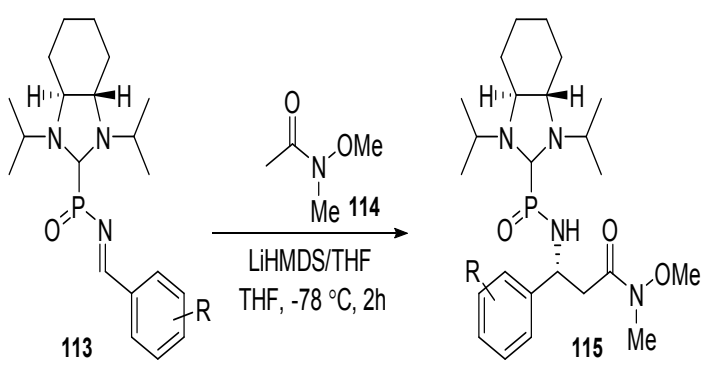

Scheme 25. Synthesis of N-Phosphonyl b-Amino Weinreb Amides

Meanwhile, Huet al et., ${ }^{39}$ reported a wonderful reagent, $\mathrm{P}\left[\mathrm{NCH}_{3}\left(\mathrm{OCH}_{3}\right)\right]^{3}$, for the direct synthesis of Weinreb amides 120 from carboxylic acids 119 (Scheme 26). So firstly, treatment N,O-dimethylhydro xylaminehydrochloride 116 withPCl3116in $\mathrm{Et}_{2} \mathrm{O}$ uses triethylamine as a base to give $\mathrm{P}\left[\mathrm{NCH}_{3}\left(\mathrm{OCH}_{3}\right)\right] 3118$ in $67 \%$ yield. Secondly, $\mathrm{P}\left[\mathrm{NCH}_{3}\left(\mathrm{OCH}_{3}\right)\right] 3118$ can be utilized for the conversion of various kinds ofcarboxylic acids includedaliphatic, aromatic, stericallyhindered, and dioic acids in toluene into the expected Weinrebamide products in excellent yields employing soft conditions.

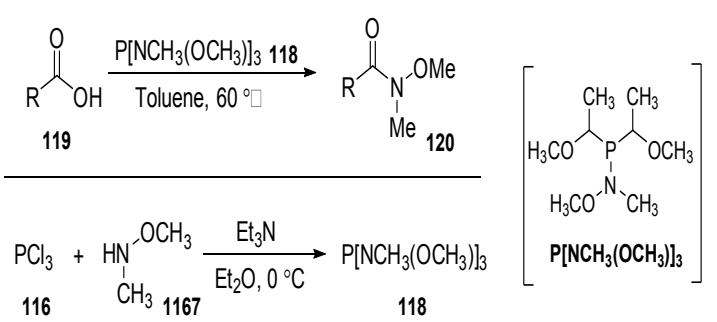

Scheme 26. Synthesis of Weinreb Amides Directly from Carboxylic Acids using $\mathrm{P}\left[\mathrm{NCH}_{3}\right]\left(\mathrm{OCH}_{3}\right)_{3}$ reagent

\section{CONCLUSION}

Newly, assorted investigations have itemized the utilization of Weinreb amide developments as an awesome intermediate in natural blend reaction. In this sheet, we displayed this side of the written works, including an abnormal preparation of Weinreb amides and their employments by explaining convention instances of these procedures. Besides, this paper contains a definitive finish of the specialists and conveniently outfits reaction data for the exceedingly significant reaction and numerous indications to the regional literature.

\section{ACKNOWLEGEMENT}

We acknowledge the University of Zakho, Faculty of Science, Department of Chemistry for providing all the facilities.

\section{Conflicts of Interest}

The authors declare no conflict of interest.

\section{REFERENCES}

1. (a) Overh $\mathrm{M}$ and Hecht S. M; A concise synthesis of the antifungal agent (+)-preussin. J. Org. Chem.,1994, 59, 4721-4722; (b) Kuethe J. T, Comins D. L; Addition of metallo enolates to chiral 1-acylpyridinium salts: Total synthesis of $(+)$-cannabisativine. Org. Lett., 2000, 2, 855-857; (c) Davis F. A, Chao $B$; Alkaloid Synthesis Using Chiral $\delta$-Amino $\beta$-Ketoesters: A Stereoselective Synthesis of (-)-Lasubine II. Org. Lett., 2000, 2, 2623-2625; (d) Smith A. B, Beauchamp T. J, LaMarche M. J, Kaufman, M. D, Qiu Y, Arimoto H, Jones
D. R, Kobayashi K; Evalution of a gram-scale synthesis of (+)-discodermolide. J. Am. Chem. Soc., 2000, 122, 8654-8664; (e) Crimmins M. T, Stanton M. G, Allwein S. P ;Asymmetric Total Synthesis of (-)-Laulimalide: Exploiting the Asymmetric Glycolate Alkylation Reaction. J. Am. Chem. Soc., 2002, 124, 5958-5959; (f) Vosburg D. A, Vanderwal C. D, Sorensen E. J;A synthesis of (+)-FR182877, featuring tandem transannular Diels- Alder reactions inspired by a postulated biogenesis. J. Am. Chem. Soc., 2002, 124, 4552-4553; (g) Cheung A. 
K, Snapper M. L; Total Syntheses of (+)-and (-)-Cacospongionolide B: New Insight into Structural Requirements for Phospholipase A2 Inhibition. J. Am. Chem. Soc., 2002, 124, 11584-11585; (h) Mohammed S; Synthesis of some Substituted-1,3,4-Oxadiazoles, Thiadiazoles and 1,2,4-Triazoles. J. Edu. Sci., 2009, 22, 29: (i) Evans D, Trotter B; Enantioselective total synthesis of altohyrtin C (spongistatin 2). Tetrahedron., 1999, 55, 867;(j) Evans DA, Coleman PJ, Dias LC, Angew. Chem., Int. Ed. Engl., 1997, 36, 2738; (k) He W, Huang J, Sun X, Frontier A. J; Total synthesis of $( \pm)$-merrilactone $A$. J. Am. Chem. Soc., 2008, 130, 300-308; (I) Custar DW, Zabawa TP, Scheidt KA; Total synthesis and structural revision of the marine macrolide neopeltolide. J. Am. Chem. Soc., 2008, 130, 804-805;(m) Maher K A, Mohammed S $R$, Metal complexes of Schiff base derived from salicylaldehyde-A review, International Journal of Current Research and Review., 2015, 7(2), 6.

2. (a) Nahm S, Weinreb S. M; N-Methoxy$\mathrm{N}$-methylamides as effective acylating agents. Tetrahedron Lett., 1981, 22, 38153818; (b) Khlestkin VK, Mazhukin DG; Recent advances in the application of $\mathrm{N}$, O-dialkylhydroxylamines in organic chemistry. Current Organic Chemistry., 2003,7, 967993; (c) Khalid M, Shireen M; Recent Advances in the Multicomponent Synthesis of Pyrano [2, 3-c] pyrazole derivatives. Res. J. Chem. Environ., 2019, 23(10), 139-156; (d) Mohammed S, Dawood A, Mahmmoud $M$; Synthesis, Identification and Biological Activity of some Schiff Bases derived from 1,5-diamino naphthalene substrate Res. J. Chem. Environ., 2019, 23(9), 108-112; (e) Maher Khalid, Mohammed S; Recent Halocyclization Reactions of Alkenes-A Review. Indian J. Hetero. Chem., 2018, 28, 507-527.; (f) Maher K, Mohammed S; Recent Trifluoromethylation Reactions. A Mini Review Paper. Orient. J. Chem., 2018, 34, 2708; (g) Maher K, Mohammed S; Crown Ether Schiff bases and Their Complexes: Recent Advances Review. Orient. J. Chem., 2018, 34, 17011718; (h) MAHER K, Schiff Bases Derived from 2-Hydroxynaphthalene-1-carbaldehyde and their Metal Complexes, Asian Journal of Chemistry., 2018, 30(6), 1171-1182
3. (a) Balasubramaniam S, Aidhen IS; The growing synthetic utility of the Weinreb amide. Synthesis., 2008, 2008, 3707-3738; b) Sibi $\mathrm{MP}$; Chemistry of $\mathrm{N}$-methoxy- $\mathrm{N}$-methylamides. Applications in synthesis. A review. Organic preparations and procedures international., 1993, 25, 15-40; (c) Beniazza R, Liautard V, Poittevin C, Ovadia B, Mohammed S, Robert F, Landais Y; Free-Radical Carbo-Alkenylation of Olefins: Scope, Limitations and Mechanistic Insights. Chem-A. Eur. J., 2017, 23, 24392447; (d) Mohammed S; Development of new radical processes: approaches toward the synthesis of Eucophylline. Ph.D. Thesis, Bordeaux1 University, Bordeux, France., 2014; (e) Khalid M, Mohammed S; Recent Free-Radical Reactions, Asian J. Chem., 2019, 31(1), 25-40; (f) Mohammed S, Khalid $\mathrm{M}$; High Efficient of the Intermolecular Radical Reactions through three-Component Carbo-Oximation Process using new ready available Sulfonyl oxime. Orient. J. Chem., 2015, 31, 1319-1326; (g) Mohammed S, Khalid M; Novel Free-Radical Mediated Carboalkenylation of Olefins Processes Starting from Ready Available Benzylketone and Weinreb Amide Xanthate as a Electrophilic Radical Precursors and E-Sulfone Acceptor. J. Indian Chem. Soc., 2015, 92, 1569-1578; ChemInform., 2016, 47(26), 1264-1275.

4. (a) Ruiz J, Sotomayor N, Lete E; Parhamtype cycliacylation with Weinreb amides. Application to the synthesis of fused indolizinone systems. Org. Lett., 2003, 5, 1115-1117; (b) Taillier C, Bellosta V, Meyer C, Cossy J; Synthesis of $\omega$-Hydroxy Ketones from $\omega$-Benzyloxy Weinreb Amides by Using a Chemoselective Nucleophilic Addition/ Birch Reduction Process. Org. lett., 2004, 6, 2145-2147; (c) Mohammed S, Maher K; Synthesis and Spectral Characterization of 1, 5-Naphthyridine Derivatives through CrossCoupling Suzuki Reaction. Indian J. Hetero. Chem., 2019, 29, 199-203; (d) Mohammed S, Khalid M; A facile Synthesis of Quinazolinone Derivatives Through Vilismeier Intermediate. Indian J. Hetero. Chem., 2017, 27(3), 83-87: (e) Mohammed S; A Novel Synthetic Route of Fused Tricyclic Framework Quinoline Derivatives from Readily Available Aliphatic Amino Carboxylic Acid Substrates, Orient. J. Chem., 2019, 35(2), 611-617; (f) Mohammed 
S, Maher K, Dawood A; A Flexible Protocol for the Preparation of Quinoline Derivatives through Mitsunobu Reaction and Aza-Wittig Intermediate, Indian J. Hetero. Chem., 2017, 27(4), 457-462.

5. Conrad R. M., Grogan M. J., Bertozzi, C. R., Stereoselective synthesis of myo-inositol via ring-closing metathesis: A building block for glycosylphosphatidylinositol (GPI) anchor synthesis. Organic letters., 2002, 4, 1359-1361.

6. Dehmlow E. V., Kinnius J., Buchholz M., Hannemann D. Preparation of Cyclobutyl Group Carrying Cyclobutanones and Related Synthetic Building Blocks. Journal für praktische Chemie., 2000, 342, 340-347.

7. (a) Murphy J. A., Commeureuc A. G., Snaddon T. N., McGuire T. M., Khan T. A, Hisler K., Dewis M. L, Carling R., Direct conversion of $\mathrm{N}$-methoxy- $\mathrm{N}$-methylamides (Weinreb amides) to ketones via a non classical Wittig reaction. Org. lett., 2005, 7, 1427-1429: (b) Hisler K., Tripoli R., Murphy J. A., Reactions of Weinreb amides: formation of aldehydes by Wittig reactions. Tetrahedron Lett., 2006, 47, 6293-6295.

8. (a) Braun M, Waldmüller D; Simple ThreeStep Synthesis of (R)-and (S)-4-Amino3-hydroxybutanoic Acid (GABOB) by Stereoselective Aldol Addition. Synthesis., 1989, 856-858; (b) Sawamura M, Nakayama Y, Kato T, Ito Y, Gold (I)-Catalyzed Asymmetric Aldol Reaction of N-Methoxy-N-methyl-. alpha.-isocyanoacetamide -alpha.IsocyanoWeinreb Amide). An Efficient Synthesis of Optically Active. beta.-Hydroxy. alpha.-Amino Aldehydes and Ketones. J. Org. Chem.,1995, 60, 1727-1732; (c) Gibson C.L, Handa S; An expedient synthesis of (R)(+)-umbelactone. Tetrahedron Asym.,1996, 7, 1281-1284; (d) Niu T, Zhang W, Huang D, Xu C, Wang Hu H.Y; A powerful reagent for synthesis of Weinreb amides directly from carboxylic acids. Org. lett., 2009: 11: 4474-4477; (e) Moyer M. P, Shiurba J. F, Rapoport H; Metal-halogen exchange of bromoindoles. A route to substituted indoles. J. Org. Chem.,1986, 51, 5106-5110; (f) Goel O, Krolls U, Stier M, Kesten S; N-tertbutoxycarbonyl-L-leucinal. Org. Synth.,1988, 67, 69-69; (g) Theisen P. D, Heathcock C. $\mathrm{H}$; Improved procedure for preparation of optically active 3-hydroxyglutarate monoesters and 3-hydroxy-5-oxoalkanoic acids. J. Org. Chem.,1988, 53, 2374-2378; (h) Jones TK, Mills SG, Reamer R. A, Askin D, Desmond R, Volante R, Shinkai I; Total synthesis of immunosuppressant (-)-FK-506. J. Am. Chem. Soc., 1989, 111, 1157-1159; (i) AL-Niami Khalid M. M, Daoud S, Mohammed M, Najham; Synthesis of Subsituted-1,3,4Oxadiazoles-1,3,4-Thiadiazolesand1,2,4Triazolesfrom-2-(2,3-dimethy Iphenyl amino) benzoic acid. J. Edu. SCI., 2009, 22, 1-10; (J) Nitz T. J, VolkotsD. L, Aldous D. J, Oglesby R. C; Regiospecific synthesis of 3-substituted 5-alkylisoxazoles from oxime dianions and $N$-methoxy- $N$-methylalkylamides. J. Org. Chem.,1994, 59, 5828-5832.

9. Goel O, Krolls U; synthesis of $\mathrm{N}, \mathrm{O}$ Dimethylhydroxylamine hydrochloride. Organic preparations and procedures international., 1987, 19, 75-78.

10. Dineen T. A, Zaja M. A, Myers A. G; Efficient transamidation of primary carboxamides by in situ activation with $\mathrm{N}, \mathrm{N}$-dialkylformamide dimethyl acetals. J. Am. Chem. Soc., 2006, 128, 16406-16409.

11. (a) Basha A. M, and Steven M; Weinreb. "A mild, general method for conversion of esters to amides." Tetrahedron Lett.,1977, 18(48): 4171-4172: (b) Sha C. K, Huang S. J, Zhan Z. P; Anionic cyclization approach toward perhydrobenzofuranone: stereocontrolled synthesis of the hexahydrobenzofuran subunit of avermectin. J. Org. Chem., 2002, 67, 831836; c) Colobert F, Mazery R. D, Solladié G, Carreno M. C; First enantioselective total synthesis of (-)-centrolobine. Org.Lett., 2002 , 4, 1723-1725; (d) Jaipuri F. A, Jofre M. F, Schwarz K. A, Pohl N. L; Microwave-assisted cleavage of Weinreb amide for carboxylate protection in the synthesis of a (R)-3hydroxyalkanoic acid. Tetrahedron lett., 2004, 45, 4149-4152; (e) Hassan H, Mohammed S, Robert F. R, Landais Y; Total Synthesis of ( \pm )-Eucophylline. A Free-Radical Approach to the Synthesis of the Azabicyclo [3.3. 1] nonane Skeleton. Org.lett., 2015, 17, 45184521; (f) Mohammed S, Maher K; A Facile Entry to Fused Dipyrimidine: Preparation of Imidazo[1,2-a:3,4-a'] Dipyrimidine-4,9(3H)Dione and Pyrimido[1',2':4,5] Pyrazino[1,2-a] Pyrimidine-4,10(3H,6H)-Dione Derivatives. 
Indian J. Hetero. Chem., 2017, 27(3), 1-6; (g) Mohammed S, KHALID M; A Facile Protocol for the Construction of Tricyclic Framework Tetrahydrobenzo-4-nitrobenzenesulfonate, 4-methylbenzenesulfonate and [1, 8] naphthyridine Substituents from Methyl $\delta$-Lactam. Orient. J. Chem., 2015, 31(4), 2137-2146; (h) Daoud K. M, Mohammed S. R, Saeed Z. F; Synthesis and Antibacterial Activity of 2-Cinnamyl-5-Substituted1,3,4-Oxadiazole, 1,3,4-Thiadiazoles and 5-Cinnamyl-3-Substituted-1,2,4-Triazoles. Iraqi Nat. J. Chem., 2007, 102-110.

12. Shimizu T.; Osako K.; Nakata, Efficient method for preparation of $N$-methoxy- $N$ methyl amides by reaction of lactones or esters with $\mathrm{Me}_{2} \mathrm{AlCl}_{3} \mathrm{MeONHMe} \bullet \mathrm{HCl}$. T.-i. Tetrahedron Lett.,1997, 38, 2685-2688.

13. Jacobi, P. A.; Kaczmarek C. S., Udodong U. E., Bis heteroannulation. 8. Total synthesis of ( \pm )-paniculide-A. Tetrahedron Lett.,1984, 25, 4859-4862.

14. De Luca, L. De: Giacomelli G and Taddei, M; An easy and convenient synthesis of Weinreb amides and hydroxamates. The Journal of organic chemistry., 2001, 66(7): 2534-2537.

15. Douat, C; A. Heitz; A; Paris M; Martinez J; and Fehrentz,J, Post-synthesis incorporation of a lipidic side chain into a peptide on solid support. Journal of peptide science: an official publication of the European Peptide Society., 2001, 8(11), 601-614.

16. Jeong, I. H; Jeon, S. L; MinY. K and Kim B. T; A novel approach to $\beta$-trifluoromethyl enaminones. Tetrahedron letters., 2002 , 43(40), 7171-7174.

17. Ruiz, J. N; Sotomayor L. N and Lete, E; Parham-type cycliacylation with Weinreb amides. Application to the synthesis of fused indolizinone systems. Organic letters., 2003, 5(7), 1115-1117.

18. Yun, J.M; Efficient synthesis of enantiomerically pure 2-acylaziridines: Facile syntheses of N-Boc-safingol, N-Boc-D-erythrosphinganine, and $\mathrm{N}$-Boc-spisulosine from a common intermediate. The Journal of organic chemistry., 2003, 68(20), 7675-7680.

19. \#Cantel, S; Cantel, S; Heitz, A; Martinez J and Fehrentz J; Synthesis of chiral $\alpha$-amino aldehydes linked by their amine function to solid support. Journal of peptide science: an official publication of the European Peptide
Society., 2004, 10(9), 531-534.

20. Hioki, K; Kobayashl, H; Ohkihara, R; Tani $\mathrm{S}$ and Kunishima, M; Preparation of Weinreb amides using 4-(4, 6-dimethoxy-1, 3, 5-triazin-2-yl)-4-methylmorpholinium chloride (DMT-MM). Chemical and pharmaceutical bulletin., 2004, 52(4), 470-472.

21. Jeong, L. H; Jeon, S. L; Kim M. S and Kim, B. $\mathrm{T}$; New approaches to $\beta$-trifluoromethylated enone derivatives. Journal of fluorine chemistry., 2004, 125(11), 1629-1638.

22. Parhi A. K and Franck, R. W; A Weinreb nitrile oxide and nitrone for cycloaddition. Organic letters., 2004, 6(18), 3063-3065.

23. Woo, J. C; Fenster E and Dake, G. R; A convenient method for the conversion of hindered carboxylic acids to $N$-methoxy$N$-methyl (Weinreb) amides. The Journal of organic chemistry., 2004, 69(25), 89848986.

24. Lee J. I and Hung, H. J; A New Synthesis of $\mathrm{N}$-Methoxy-N-methylamides from S-2-Pyridyl Thiocarbamate and Grignard Reagents. Journal of the Korean Chemical Society., 2005, 49(6), 609-612.

25. Davis, F. A; Nolt, M. B; Wu, Y. ; Prasad, K. R; Li, D, Yang, B; K. Bowen, K; Lee, S. H and Eardley, J. H; Asymmetric synthesis of $\beta$-amino carbonyl compounds with $N$-sulfinyl $\beta$-amino Weinreb amides. The Journal of organic chemistry., 2005, 70(6), 2184-2190.

26. Murphy, J. A; lien, G. A; Commeureuc J and Thomas, N; Direct conversion of N-methoxy$\mathrm{N}$-methylamides (Weinreb amides) to ketones via a nonclassical Wittig reaction. Organic letters., 2005, 7(7), 1427-1429.

27. Conrad, K; Hsiao Y and Miller, R; A practical one-pot process for $\alpha$-amino aryl ketone synthesis. Tetrahedron letters., 2005, 46(49), 8587-8589

28. Aron, R; Coffin, A; Roussell, M; Tserlin, E and Pelkey E. T; Regiocontrolled synthesis of pyrrole-2-carboxaldehydes and 3-pyrrolin2-ones from pyrrole Weinreb amides. The Journal of organic chemistry., 2006, 71(17), 6678-6681.

29. Hisler, J.A. and Murphy J. A: , Reactions of Weinreb amides: formation of aldehydes by Wittig reactions. Tetrahedron letters., 2006, 47(35), 6293-6295. 
30. Martinelli, J. R, Freckmann D. M and Buchwald, S. L; Convenient method for the preparation of weinreb amides via Pd-catalyzed aminocarbonylation of aryl bromides at atmospheric pressure. Organic letters., 2006, 8(21), 4843-4846

31. Qu B and Collum, D. B; Mechanism of acylation of lithium phenylacetylide with a Weinreb amide. The Journal of organic chemistry., 2006, 71(18), 7117-7119.

32. Persson $\mathrm{T}$ and Nielsen, J; Synthesis of $N$-methoxy- $N$-methyl- $\beta$-enaminoketoesters: New synthetic precursors for the regioselective synthesis of heterocyclic compounds. Organic letters., 2006, 8(15), 3219-3222.

33. Davis, F. A and Song,M; Asymmetric Synthesis of syn- $\alpha$-Substituted $\beta$-Amino Ketones by Using Sulfinimines and Prochiral Weinreb Amide Enolates. Organic letters., 2007, 9(12), 2413-2416.

34. Han, K and Kim, M; Direct synthesis of Weinreb amides from carboxylic acids using triphosgene. Letters in Organic Chemistry., 2007, 4(1), 20-22.
35. Jeon, S. L; Kim, J.K; Son, J. B; Kim B. T and Jeong, I. $\mathrm{H}$; One pot synthesis of novel $\alpha, \beta$-dichloro- $\beta$-trifluoromethylated enones and their application to the synthesis of trifluoromethylated heterocycles. Journal of fluorine chemistry., 2007, 128(2), 153-157.

36. Deagostino, A; Larini, P; Ernesto. G and Pizzuto L; Synthesis of Weinreb amides via Pd-catalyzed aminocarbonylation of heterocyclic-derived triflates. The Journal of organic chemistry., 2008, 73(5), 1941-1945.

37. S. Hirner, S; O. Magnus $O$ and Somfai, P; Synthesis of aryl glycines by the $\alpha$ arylation of Weinreb amides. Angewandte Chemie International Edition., 2008, 47(10), 1907-1909.

38. Kaur, P; Nguyen T and Li, G; Chiral $N$-Phosphonylimine Chemistry: Asymmetric Synthesis of $N$-Phosphonyl $\beta$-Amino Weinreb Amides. European Journal of Organic Chemistry., 2009, 2009(6), 912-9169.

39. Niu, T; Zhang, W. G; Huang, Da; Xu C. H and Yulai, $\mathrm{H}$ :. W; A powerful reagent for synthesis of Weinreb amides directly from carboxylic acids. Organic letters., 2009, 11(19), 4474-4477. 